\title{
Intelectuais, mídias e universidade pública em contexto de peleja'
}

\author{
Intellectuals, media and public university in a battle context
}

\section{Sergio Micelia}

Resumo A palestra de Sergio Miceli trata da relevância que a imprensa escrita, televisiva e demais agentes e meios comerciais tomaram ao longo do tempo no Brasil. Segundo o seu diagnóstico, eles passaram a disputar a hegemonia intelectual com o setor tradicionalmente produtor de conhecimento: a universidade. Isso posto, cabe fazer uma reflexão sobre o papel do intelectual na universidade e a busca por soluções nessa guerra simbólica.

Palavras-chave Universidade Pública; Imprensa; Intelectuais.

Abstract Sergio Miceli's lecture approaches the relevance that written press and television, as well as other agents and commercial means, took over time in Brazil. According to his diagnosis, they began to dispute the intellectual hegemony with the traditionally knowledge producing sector: the university. That said, it should be time to reflect upon the role of the intellectual in the university and the search for solutions in this symbolic war.

Keywords Public University; Press; Intellectuals.

Hesitei muito em aceitar o convite porque não me agrada discorrer sobre temas que não estudo e ainda mais nesta mesa de balanço político. No entanto, em tempos de crise generalizada, tenho de me manifestar. Parte do que gostaria de suscitar no debate tem a ver com a área da educação. Mas antes tenciono tratar do enfrentamento da indústria cultural com a universidade, e vice-versa: a mídia em postura agressiva por razões defensivas, enquanto a universidade está imersa numa conjuntura de escassez de recursos, acuada por um desígnio político.

No Brasil, a expansão do ensino superior, o incremento dos diplomados, a democratização acelerada do acesso à educação sucedeu por iniciativa do poder público, em contexto de competição com a indústria cultural cumprindo funções

1 Palestra proferida no encerramento do I Seminário de Sociologia da Cultura, realizado na Faculdade de Filosofia, Letras e Ciências Humanas da Universidade de São Paulo entre os dias 7 e 9 de dezembro de 2016. Na mesma mesa constavam os professores Maria Arminda do Nascimento Arruda (USP) e Marcelo Siqueira Ridenti (Unicamp).

a Professor Titular do Departamento de Sociologia da Faculdade de Filosofia, Letras e Ciências Humanas da Universidade de São Paulo. 
para-pedagógicas. Nos países europeus, e mesmo na vizinha Argentina, por conta da escolaridade obrigatória e universal, a televisão jamais desfrutou da centralidade lograda aqui.

Houve esperança, em determinado momento, de que o declínio da audiência televisiva, somado à ampliação do lazer privado - tópicos abordados por Raymond Williams no livro Televisão: Tecnologia e Forma Cultural (Williams, 2016) pudesse alterar a situação. A expansão da Netflix, do streaming, da TV a cabo, redundaria no recuo do investimento publicitário e da legitimidade de convocatória da mídia sobre a população pouco escolarizada. Houve um declínio de audiência da novela, do noticiário, mas não um recesso proporcional da televisão como a mídia mais pujante no tocante à concentração do investimento publicitário.

Em compensação, ou melhor, em contrapartida, a imprensa está a braços com ameaças à sobrevivência, despedindo centenas de jornalistas, e buscando equilibrar o negócio entre suporte impresso e internet, na tentativa de emular o projeto em curso ora implementado, por exemplo, pelo The New York Times, The Guardian, Le Monde, entre outros. Entretanto, ao contrário da parceria desses veículos cosmopolitas mencionados com sua respectiva inteligência nacional, os principais diários no país - Folha de São Paulo, Globo e O Estado de S. Paulo - se voltaram contra a universidade pública tendo em mira aqueles setores do campo intelectual dotados de autonomia material e de voz autoral. A universidade pública se tornou, na última década, um alvo prioritário de crítica, de demonização, de detração. Como se fosse possível dispensar a instituição que vem suprindo a mão de obra indispensável à existência e à continuidade da indústria cultural.

Roberto Schwarz, quando do golpe de 1964, escreveu um artigo inspirado em número especial sobre o Brasil na revista Les Temps Modernes, mostrando naquele momento que a esquerda continuava detendo a hegemonia no campo cultural (Schwarz, 1992). Hoje, o que enxergamos em termos de enfrentamento? As reportagens e matérias na mídia impressa execram o ensino público e enaltecem as empreitadas do ensino particular, sem falar na veiculação maciça de publicidade paga por esses grupos de investidores e corporações, algumas multinacionais. Suplementos especiais sobre o ensino privado, cobertura favorável nos editoriais, em paralelo à insistente desqualificação da universidade pública, como se onerasse o contribuinte ao "subsidiar" uma classe de docentes tidos como "privilegiados". Campanhas sistemáticas de desqualificação e de desmonte da inteligência. A Folha de São Paulo publicou há muitos anos uma lista dos que eles chamavam de 
“improdutivos". ${ }^{1}$ E mais recentemente, divulgou o salário dos professores, como se tal informação, por si só, fosse sintoma dos desmandos de privilégio na distribuição de renda dos produtores da atividade intelectual. ${ }^{2}$

A razão da postura anti-intelectualista da imprensa antiacadêmica, anti-universidade pública, tem muito a ver com o chamado insistente a favor do desmonte do Estado, em especial naquelas atividades voltadas para democratizar o acesso, educação e saúde. Outro indicador sugestivo: a editora Três Estrelas, pertencente ao Grupo Folha, privilegia a difusão de textos inovadores, na fachada, mas de fato de alguns livros obscurantistas, como, por exemplo, a parolagem de um sujeito que discute as teorias raciais sustentando um novo racialismo, como se fosse grande novidade. Ou então, uma defesa da sociobiologia, um tipo de raciocínio e de argumentação, reiterados por certos colunistas, especialistas da doxa rasteira, os quais se pronunciam sobre quaisquer assuntos, girando em torno de uma suposta natureza humana, do ser; eles sabem o que é o homem, a mulher, o desejo, como a mulher gosta do homem, o homem da mulher, e assim por diante. São aulas insossas de um ersatz de fenomenologia, de patologia, de morfologias despidas de contingências históricas. Eis o aspecto mais anedótico.

Quero chamar a atenção para o que está em jogo se nós entendermos a atividade intelectual não como atividade reservada a intelectuais credenciados, mas como práticas concorrentes no interior de um mercado de bens simbólicos, um sistema integrado de produção cultural. O que está em disputa em meio a tais enfrentamentos? O alvo perseguido pela imprensa e pela televisão transparece em entrevistas e debates cuja agenda segue à risca as pautas políticas da mídia. A televisão também se lançou com energia nesse prélio, não para garantir audiência, e tampouco por cálculo de investimento econômico, visando sobretudo a conquista de alguma autoridade cultural: explicita a política de defesa arrogando-se o status de poder se constituir em instância legítima de consagração cultural - o nó do imbróglio.

Vale a pena lembrar a notável entrevista com Renato Janine Ribeiro no programa Roda Viva, ${ }^{3}$ ao tempo de sua gestão como Ministro da Educação. Saiu-se com brilho diante de uma bancada de "experts" em educação, adiante convocados pelo governo Temer para implementar políticas privatistas na área. Lembrei do entrevero porque sinalizou um dado relevante: as alusões às divergências em torno

1 O valor dos improdutivos. Folha de S. Paulo, p. A2, 24 fev. 1988.

2 Disponível em https://www1.folha.uol.com.br/infograficos/2014/11/117724-ranking-de-salarios-da-usp.shtml, acessado em 29 jun. 2018.

3 Disponível em https://www.youtube.com/watch?v=2b4NjuCvK4s, acessado em 29 jun. 2018. 
do encaminhamento da Lei de Diretrizes e Bases, o qual se estendeu por anos de discussão, evidenciaram o fato de que os interlocutores naquele momento incluíam os representantes dos sindicatos de docentes, de funcionários, os porta-vozes da associação de reitores, das corporações patronais do ensino médio, de congregações católicas, ou seja, um confronto efetivo dos grupos de interesse atuantes na área. E hoje, o que vemos na discussão? Um coletivo de ONGs e de entidades de assessoria política, a que se juntam os emissários desses lobbies no Congresso. Uma rede articulada de grupos privados e de investidores.

Em seminário recente de que participei, no Rio de Janeiro, a respeito da recepção da obra de Pierre Bourdieu no Brasil, ${ }^{4}$ tive a oportunidade de ouvir a competente exposição de Ana Maria de Almeida sobre o assunto, em que ressaltava o número expressivo de sociólogos e de cientistas sociais contratados por esses organismos e think tanks, aferrados a projetos privatistas de intervenção no ensino, exercendo uma advocacia justificadora dos interesses de tais entidades na discussão do Plano Nacional de Educação.

O problema crucial consiste na luta política em curso no universo cultural. Vivemos isso cada dia. Pode-se perceber o que se passa pelo viés anedótico dos colunistas de direita, feição menor da conjuntura. Cumpre reagir e contestar tal reclamo de autoridade cultural monopolista: rechaçar o projeto de a mídia se converter em instância decisiva de juízo. A mera existência da universidade pública suscita incômodo. Não é por acaso que pululam subentendidos e chacotas sobre intelectuais, alguns deles vazados em termos caricatos, nomeando assim, pelo avesso, o chão pretensamente realista do que se alardeia como nefasto. As invectivas contra a sociologia, por exemplo, constam até de escritos de críticos de cinema, os quais desqualificam um filme como "demasiado sociológico". Trata-se de um trabalho persistente e azeitado de sapa cultural, permeando diversas frentes de detração que apelam a estereótipos da atividade intelectual.

Mas não queria acabar em tom de crítica negativa. A iniciativa desse seminário revela a feição coletiva do trabalho intelectual. Uma experiência marcante de minha iniciação como sociólogo, durante o período como doutorando em Paris, me fez ver o trabalho intelectual como atividade que se fazia em equipe, fruto de um coletivo. Havia uma divisão do trabalho bastante diferente da ideia que eu trazia daqui. A Faculdade de Filosofia, Letras e Ciências Humanas da USP costuma valorar o feitio artesanal do trabalho intelectual, em detrimento de outros aspectos.

4 Colóquio Pierre Bourdieu no Rio de Janeiro - 15 anos da morte do escritor, realizado entre os dias 05 e 09 de dezembro de 2016. Ver http://www.ensp.fiocruz.br/portal-ensp/coloquiobourdieu/, acessado em 29 jun. 2018. 
Este seminário resultou de uma empreitada em parceria, cuja montagem decerto suscitou desavenças e dissensões. As lutas constituem o fulcro da vida intelectual. A experiência parisiense teve continuidade após meu retorno. Quis realizar o projeto de pesquisa sobre a história das ciências sociais no Brasil por meio de uma equipe diversificada e multidisciplinar, cabendo a cada pesquisador um objeto, na tentativa de reeditar, à brasileira, a iniciação francesa.

Ora faço um fecho polêmico porque o assunto me incomoda. Na universidade, tem havido inúmeras greves, ocupações, cadeiraços. Apesar da necessidade dessas manifestações, por vezes tais atitudes se tornam abusivas e revertem contra nós, contra nossos interesses; constituem um tiro no pé da atividade intelectual e da vida institucional na universidade. Não estamos assim contribuindo para a legitimação de nossa atividade, ou nutrindo o reforço da autoridade intelectual, política e institucional. Reconheço que quase sempre tivemos aumento salarial aqui em função de uma greve liderada pela Adusp (Associação dos Docentes da Universidade de São Paulo); respeito de verdade a Adusp e a política consistente de defesa de nossos interesses. Todavia, tem sido desastroso o descalabro entre esse trabalho político de êxito e o que vem acontecendo nos últimos anos. Teremos de fixar um limite. A saída consiste em dirigir nossos esforços e investimentos para a atividade intelectual, e temos de levar a sério tal empenho. Eis a única garantia de continuidade ao trabalho já acumulado pelos que nos precederam, trabalho que está na raiz de uma tradição intelectual de impacto, um tesouro de interpretações, de análises, de diagnósticos da sociedade brasileira. O patrimônio desta universidade é fenomenal - não apenas acervos documentais preciosos, coleções de livros e de obras de arte -, mas sobretudo a formação de gerações sucessivas da inteligência brasileira em todos os campos do saber. Podemos e devemos fazer reivindicações, campanhas, greves, motivadas e oportunas, mas estamos levando tais pleitos à beira do suicídio institucional.

Também não estou convencido do acerto de tais condutas em nome de agendas identitárias; tais demandas são válidas e devem ser discutidas, mas não podem se converter em norma exclusiva e predominante de avaliação e de juízo dos rumos de uma instituição universitária, ora exposta a tantos fogos. Tivemos um treinamento que nos ensinou a tolerância, a apreciar e encorajar a diversidade. Qual é a inclinação da maioria dos professores? A de que isso tudo é aceitável? Estamos militando contra a instituição e dando pólvora às pretensões heterônomas das instâncias e grupos de interesse empenhados em desacreditar a autoridade simbólica da universidade. 
Estou chamando a atenção para a parcela de nossa responsabilidade na história do que está acontecendo intramuros; os impasses não derivam de forças externas. Temos contribuído e muito para o desmonte institucional em andamento, e não estou me colocando fora ou acima do que se passa. Meus cumprimentos a vocês que organizaram o evento como homenagem ao trabalho intelectual. Como cientistas sociais, não estamos obrigados à profecia política; fomos treinados a empreender um trabalho intelectual consistente sobre temas e objetos de nossa competência. Eis a única força que possuímos, e o seminário é a expressão desse legado.

\section{REFERÊNCIAS BIBLIOGRÁFICAS}

O valor dos improdutivos. Folha de S. Paulo, 24 fev. 1988.

Ranking de salários da USP. Folha de S. Paulo, 16 nov. 2014

Schwarz, Roberto. “Cultura e Política: 1964-1969”. In: Schwarz, Roberto. O pai de família e outros estudos. Rio de Janeiro: Paz e Terra, 1992, p. 61-92.

Williams, Raymond. Televisão: tecnologia e forma cultural. São Paulo: Boitempo, 2016. 